\title{
Predictors of first-line antiretroviral therapy discontinuation due to drug-related adverse events in HIV-infected patients: a retrospective cohort study
}

Mattia CF Prosperi ${ }^{1,2}$, Massimiliano Fabbiani ${ }^{1}$, Iuri Fanti ${ }^{1}$, Mauro Zaccarelli $i^{3,4^{*}}$, Manuela Colafigli ${ }^{1}$, Annalisa Mondi ${ }^{1}$, Alessandro D'Avino ${ }^{1}$, Alberto Borghetti ${ }^{1}$, Roberto Cauda ${ }^{1}$ and Simona Di Giambenedetto ${ }^{1}$

\begin{abstract}
Background: Drug-related toxicity has been one of the main causes of antiretroviral treatment discontinuation. However, its determinants are not fully understood. Aim of this study was to investigate predictors of first-line antiretroviral therapy discontinuation due to adverse events and their evolution in recent years.

Methods: Patients starting first-line antiretroviral therapy were retrospectively selected. Primary end-point was the time to discontinuation of therapy due to adverse events, estimating incidence, fitting Kaplan-Meier and multivariable Cox regression models upon clinical/demographic/chemical baseline patients' markers.

Results: 1,096 patients were included: 302 discontinuations for adverse events were observed over 1,861 person years of follow-up between 1988 and 2010, corresponding to an incidence (95\% Cl) of 0.16 (0.14-0.18). By Kaplan-Meier estimation, the probabilities $(95 \% \mathrm{Cl})$ of being free from an adverse event at 90 days, 180 days, one year, two years, and five years were $0.88(0.86-0.90), 0.85$ (0.83-0.87), 0.79 (0.76-0.81), 0.70 (0.67-0.74), 0.55 (0.50-0.61), respectively. The most represented adverse events were gastrointestinal symptoms (28.5\%), hematological (13.2\%) or metabolic (lipid and glucose metabolism, lipodystrophy) (11.3\%) toxicities and hypersensitivity reactions (9.3\%). Factors associated with an increased hazard of adverse events were: older age, CDC stage C, female gender, homo/ bisexual risk group (vs. heterosexual), HBsAg-positivity. Among drugs, zidovudine, stavudine, zalcitabine, didanosine, full-dose ritonavir, indinavir but also efavirenz (actually recommended for first-line regimens) were associated to an increased hazard of toxicity. Moreover, patients infected by HIV genotype F1 showed a trend for a higher risk of adverse events.

Conclusions: After starting antiretroviral therapy, the probability of remaining free from adverse events seems to decrease over time. Among drugs associated with increased toxicity, only one is currently recommended for first-line regimens but with improved drug formulation. Older age, CDC stage, MSM risk factor and gender are also associated with an increased hazard of toxicity and should be considered when designing a first-line regimen.
\end{abstract}

Keywords: HIV, HAART, Toxicity, Side effects, Therapy-naïve

\footnotetext{
* Correspondence: mauro.zaccarelli@gmail.com

${ }^{3}$ Viral Immunodeficiency Unit, National Institute for Infectious Diseases

"Lazzaro Spallanzani", Rome, Italy

${ }^{4}$ Clinical Department, National Institute for Infectious Diseases "Lazzaro

Spallanzani", Via Portuense 292, 00149 Rome, Italy

Full list of author information is available at the end of the article
} 


\section{Background}

Combination antiretroviral therapy (cART) has markedly changed the prognosis of HIV-infected patients, reducing AIDS-related morbidity and mortality [1]. Rates of virological failure during first line regimens are decreasing both in clinical trials and in studies performed during routine clinical practice $[2,3]$. However, drug-related adverse events and toxicities are increasingly recognized [4-7] and represent one of the most common reasons for treatment discontinuation or switch [2,3,8-11]. In recent years, the introduction of newer antiretroviral agents with improved efficacy and tolerability profiles has allowed for a decline of treatment-limiting toxic effects; however, drug-related adverse events still represent an issue of concern.

Treatment-limiting cART toxicity has been associated with several factors such as demographical characteristics, drug-drug interactions, co-morbidities and recently genetic factors [12]. However, determinants of toxicity are not fully understood. In particular, the role of newer and apparently better tolerated antiretroviral drugs needs to be fully investigated. Moreover, the influence of baseline chemistry remains to be elucidated.

The aim of this study is to investigate predictors of first-line antiretroviral therapy discontinuation due to adverse events and their evolution in more recent years, characterized by an increased use of regimens with better tolerability profiles. In particular, the analysis is focused on the evaluation of baseline demographic and clinical characteristics, prescribed drugs and chemical parameters which could represent objective tools to tailor regimens on patients' characteristics.

\section{Methods}

HIV-infected patients followed up at the Infectious Diseases Clinic of the Catholic University of the Sacred Heart (CUSH) in Rome, Italy, starting a first-line antiHIV antiretroviral therapy, were screened retrospectively via the electronic CUSH data base, which includes data on more than 4,300 HIV-infected patients, with the first available anti-HIV therapy record dated 1988. All patients included in the data base had previously signed an informed consent to be included in observational studies. Access and data analyses of the CUSH data base are regulated by an institutional internal ethics committee and conform to Italian and European privacy legislations. The latest available updated version (up to January 2011) of the CUSH data base was used.

The baseline time was the start date of the anti-HIV antiretroviral therapy. The end-point of interest was the discontinuation date of the first-line anti-HIV antiretroviral therapy. Discontinuation was defined as stopping any antiretroviral drug for at least 2 weeks or switching (changing one or more drugs) to another regimen; the only exception was a substitution of lamivudine with emtricitabine or vice-versa, because it could simply reflect a shift to a fixed dose formulation of tenofovir-emtricitabine, abacavir-lamivudine or zidovudinelamivudine. An adverse event was marked if the reason of discontinuation or switch (or eventually a concomitant death) was an event corresponding to toxicity or allergy; otherwise data were censored at that time point or at the latest available time point if the patient did not stop that therapy, following a cause-specific approach. All discontinuation causes were ascertained by electronic and clinical reports (see Table 1 for categories besides the adverse event definition). In case of a decease event without a prior therapy discontinuation date, data were censored as well. First-line anti-HIV antiretroviral therapies with a known stop date, but unknown reason of stop or decease, were not included in the study population.

Covariates of interest, contemporary or the closest previous to the baseline date, were: calendar year, patient's gender, age, nationality, risk group, first date of HIV-positive antibody test, CDC stage, viral subtype, anti-HIV antiretroviral therapy, HIV-RNA load, CD4 ${ }^{+}$ T cell count, hepatitis C co-infection (HCVAb), hepatitis B co-infection (HBsAg), anti-HCV interferon/ribavirin treatment, anti-Mycobacterium Tuberculosis (TB) therapy, anti-Pneumocystis jirovecii pneumonia (PCP) therapy, other antibiotic treatments, other concomitant (prescription or over-the-counter) drugs exposure, total bilirubin, total cholesterol, hemoglobin, glucose, glutamate pyruvate transaminases (GPT), gamma-glutamyltransferase (gammaGT), high-density lipoprotein (HDL), low-density lipoprotein (LDL), triglycerides (TGL), and glomerular filtration rate (GFR) estimated by modification of diet in renal disease (MDRD) formula. Chemistry parameters were classified as normal, high or low according to established cut-offs [13,14] (see Table 2 for cut-off values). The covariate list was consistent with other European cohort studies $[15,16]$. Baseline chemistry variables were registered in the database only for patients starting antiretroviral therapy after 1998; when not available, they were encoded as unknown.

The antiretroviral therapy was encoded in different ways: (i) as a combination therapy of 2 nucleoside reverse transcriptase inhibitors (NRTI) +1 non-nucleoside reverse transcriptase inhibitor (NNRTI), 2 NRTI +1 protease inhibitor (PI), 2 NRTI + 1 PI boosted with ritonavir (PI/r), and other combinations; (ii) as single compounds, i.e. emtricitabine, lamivudine, abacavir, zidovudine, stavudine, zaltacibine, didanosine, tenofovir, nevirapine, efavirenz, atazanavir, fosamprenavir, indinavir, lopinavir, nelfinavir, ritonavir full or boosting dose, and saquinavir; (iii) as a combination therapy of different brand names, including those combinations with a 
Table 1 Causes of anti-HIV first-line therapy discontinuation in the study population $(n=1,096)$

\begin{tabular}{|c|c|c|c|c|c|}
\hline Type & Tot & Strata & $\mathrm{n}$ & $\%$ Over strata & $\%$ Over total \\
\hline \multirow{8}{*}{$\begin{array}{l}\text { Adverse events } \\
\text { (toxicity/allergy) }\end{array}$} & \multirow[t]{8}{*}{302 (1 death) } & Gastrointestinal & 86 & $28.5 \%$ & $7.8 \%$ \\
\hline & & Hypersensitivity & 28 & $9.3 \%$ & $2.6 \%$ \\
\hline & & Central nervous system & 18 & $6.0 \%$ & $1.6 \%$ \\
\hline & & Hepatic & 14 & $4.6 \%$ & $1.3 \%$ \\
\hline & & $\begin{array}{l}\text { Metabolic (glucose or } \\
\text { lipid metabolism, lipodystrophy) }\end{array}$ & 34 & $11.3 \%$ & $3.1 \%$ \\
\hline & & Renal & 13 & $4.3 \%$ & $1.2 \%$ \\
\hline & & Hematologic & 40 & $13.2 \%$ & $3.6 \%$ \\
\hline & & Other & 69 & $22.8 \%$ & $6.3 \%$ \\
\hline \multirow[t]{11}{*}{ Other causes } & \multirow[t]{11}{*}{618} & Simplification & 252 & $40.8 \%$ & $23.0 \%$ \\
\hline & & Patient's choice & 93 & $15.0 \%$ & $8.5 \%$ \\
\hline & & Failure & 86 & $13.9 \%$ & $7.8 \%$ \\
\hline & & Regimen intensification & 59 & $9.5 \%$ & $5.4 \%$ \\
\hline & & Genotype-guided switch & 20 & $3.2 \%$ & $1.8 \%$ \\
\hline & & Low adherence & 19 & $3.1 \%$ & $1.7 \%$ \\
\hline & & End of pregnancy & 16 & $2.6 \%$ & $1.5 \%$ \\
\hline & & Structured interruption & 13 & $2.1 \%$ & $1.2 \%$ \\
\hline & & Enrolment in a new prospective study & 13 & $2.1 \%$ & $1.2 \%$ \\
\hline & & Pregnancy & 12 & $1.9 \%$ & $1.1 \%$ \\
\hline & & Other & 35 & $5.7 \%$ & $3.2 \%$ \\
\hline Non-discontinued & 176 (6 deaths) & N/A & 176 & $100 \%$ & $16.1 \%$ \\
\hline
\end{tabular}

frequency of at least 10; (iv) as $\operatorname{Truvada}^{\circledR}+$ Sustiva $^{\circledR}$, Atripla $^{\circledR}, \operatorname{Reyataz}^{\circledR}$, Kaletra ${ }^{\circledR}$, any other NRTI+PI, any other NRTI+PI/r, any other NRTI+NNRTI, and other combinations. Other compounds including enfuvurtide, maraviroc, raltegravir, darunavir, and etravirine, were not included due to their low frequency.

Statistical methods included descriptive summaries, calculation of incidence ratios and confidence intervals, Kaplan-Meier estimation for the probability of surviving an adverse event, multivariable proportional-hazard hypothesis testing, and multivariable Cox model fitting in order to identify factors associated to an increased/ reduced hazard of an adverse event happening. Effect of covariate interactions and nested model comparison via ANOVA were also carried out. All statistical analyses were carried out using $\mathrm{R}$ software (www.r-project.org).

\section{Results}

The total number of HIV-positive patients recorded in the CUSH data base (up to January 2011) was 4,388. Those with at least one anti-HIV therapy registered were 2,455 , and 1,218 for which it was the actual first-line. Of these, 1,096 had a documented reason of discontinuation or did not stop the therapy and met the inclusion criteria, starting their first-line anti-HIV therapy between year 1988 and 2010 (median 2003, interquartile range
1998-2006). Of these patients, 317 started the first-line anti-HIV therapy prior to 1999 (154 before 1997), whilst 779 afterwards (Figure 1). Tables 3 and 2 list patients' demographic/clinical characteristics and chemical markers at the baseline date, concomitant to the first-line anti-HIV therapy start date. Also, Additional file 1 shows the distribution of patients under different first-line therapy regimens per calendar year, using both encoding (i) and (iv).

The observed number of therapy discontinuations for adverse events (toxicity/allergy) was 302, over 1,861 person years of follow up, corresponding to an incidence (95\% confidence intervals, CI) of 0.16 (0.14-0.18) per person years of follow up (PYFU). Table 1 summarizes in detail the causes of anti-HIV first-line therapy discontinuation. The most represented adverse events were gastrointestinal symptoms (28.5\%), hematological (13.2\%) or metabolic (lipid and glucose metabolism, lipodystrophy) (11.3\%) toxicities and hypersensitivity reactions (9.3\%). By a Kaplan-Meier estimation, the probabilities (95\% CI) of being free from an adverse event at 90 days, 180 days, one year, two years, and five years were 0.88 (0.86-0.90), 0.85 (0.83-0.87), 0.79 (0.76-0.81), 0.70 (0.67-0.74), 0.55 (0.50-0.61), respectively. Figure 2 shows the KaplanMeier curves overall and stratified for gender, risk group, CDC stage at baseline. The test of proportional-hazard 
Table 2 Baseline chemical markers (with cut-offs) of the study population $(n=1,096)$

\begin{tabular}{|c|c|c|c|}
\hline Factor & Strata & n & $\%$ \\
\hline \multirow[t]{3}{*}{ Bilirubin } & Normal & 624 & $56.9 \%$ \\
\hline & High (>1.2 mg/dL) & 31 & $2.8 \%$ \\
\hline & Unknown & 441 & $40.2 \%$ \\
\hline \multirow[t]{3}{*}{ Total Cholesterol } & Normal & 478 & $43.6 \%$ \\
\hline & High ( $\geq 200$ mg/dL) & 107 & $9.8 \%$ \\
\hline & Unknown & 511 & $46.6 \%$ \\
\hline \multirow[t]{3}{*}{ Hemoglobin } & Low $(<12 \mathrm{~g} / \mathrm{dL})$ & 158 & $14.4 \%$ \\
\hline & Normal & 593 & $54.1 \%$ \\
\hline & Unknown & 345 & $31.5 \%$ \\
\hline \multirow[t]{3}{*}{ GammaGT } & Normal & 453 & $41.3 \%$ \\
\hline & High (>60 IU/L) & 145 & $13.2 \%$ \\
\hline & Unknown & 498 & $45.4 \%$ \\
\hline \multirow[t]{4}{*}{ Glucose } & Normal & 674 & $61.5 \%$ \\
\hline & High (>110 mg/dl) & 34 & $3.1 \%$ \\
\hline & Diabetes (>126 mg/dL) & 22 & $2.0 \%$ \\
\hline & Unknown & 366 & $33.4 \%$ \\
\hline \multirow[t]{3}{*}{$\overline{\mathrm{GPT}}$} & Normal & 561 & $51.2 \%$ \\
\hline & High (>40 IU/L) & 224 & $20.4 \%$ \\
\hline & Unknown & 311 & $28.4 \%$ \\
\hline \multirow[t]{3}{*}{$\mathrm{HDL}$} & Low $(<40$ mg/dL) & 217 & $19.8 \%$ \\
\hline & Normal & 121 & $11.0 \%$ \\
\hline & Unknown & 758 & $69.2 \%$ \\
\hline \multirow[t]{3}{*}{$\mathrm{LDL}$} & Normal & 306 & $27.9 \%$ \\
\hline & High ( $\geq 130$ mg/dL) & 12 & $1.1 \%$ \\
\hline & Unknown & 778 & $71.0 \%$ \\
\hline \multirow[t]{3}{*}{ Tryglicerides } & Normal & 383 & $34.9 \%$ \\
\hline & high ( $\geq 150$ mg/dL) & 178 & $16.2 \%$ \\
\hline & Unknown & 535 & $48.8 \%$ \\
\hline \multirow[t]{3}{*}{ MDRD } & Low $\left(<60 \mathrm{mg} / \mathrm{dL} / 1.73 \mathrm{~m}^{2}\right)$ & 20 & $1.8 \%$ \\
\hline & Normal & 694 & $63.3 \%$ \\
\hline & Unknown & 382 & $34.9 \%$ \\
\hline
\end{tabular}

assumption on the data set with the full set of covariates yielded global p-values of 0.3 and 0.8 , using the anti-HIV antiretroviral therapy encoding (ii) and (iv), respectively. The proportional hazard hypothesis could not be rejected as well with the other therapy encodings. This allowed the subsequent fit of a main-effect multivariable Cox regression model.

Table 4 reports the relative hazards of the main-effects Cox models using the two different anti-HIV antiretroviral therapy encoding (ii) and (iv). These encodings were the only ones showing significantly different (defined with a p-value $<0.05$ ) hazards among such antiHIV treatment categories, therefore encodings (i) and (iii) did not reveal differences among treatment strata.

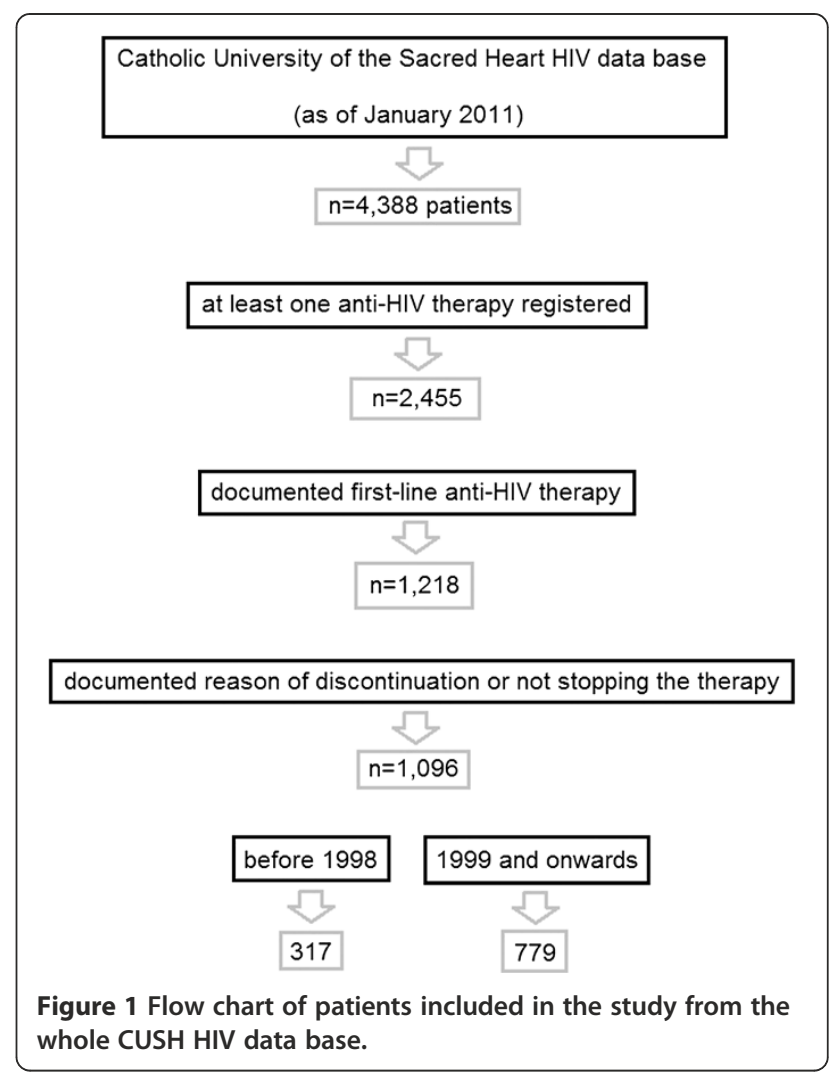

Factors associated with an increased hazard of discontinuation for adverse events were: an older age, a CDC stage $C$ vs. A, female gender, homo/bisexual risk group as compared to the heterosexual category, HBsAg positivity, zidovudine, stavudine, zalcitabine, didanosine, efavirenz, full dose ritonavir, or indinavir intake, any NRTI+PI/r intake (excluding Kaletra ${ }^{\circledR}$ and Reyataz ${ }^{\circledR}$ ) as compared to Truvada $^{\circledR}+$ Sustiva $^{\circledR}$. The relative hazard (RH) of Atripla ${ }^{\circledR}$ compared to the Truvada ${ }^{\circledR}+$ Sustiva $^{\circledR}$ category was $0.99,95 \%$ CI 0.12-8.44, $\mathrm{p}=0.99$. By changing the reference categories, we found that any NRTI+PI/r combination (excluding Kaletra ${ }^{\circledR}$ and Reyataz $^{\circledR}$ ) showed an increased risk of adverse events as compared to any other NRTI+NNRTI intake (not including Truvada ${ }^{\circledR}$, Sustiva ${ }^{\circledR}$, or Atripla ${ }^{\circledR}$ ), with a RH of 2.49 , 95\% CI 1.22-5.06, $\mathrm{p}=0.012$. In addition, any NRTI $+\mathrm{PI} / \mathrm{r}$ combination vs. Kaletra ${ }^{\circledR}$ and Reyataz ${ }^{\circledR}$ yielded a RH of 3.10, 95\% CI 1.57$6.09, \mathrm{p}=0.001$.

Also, in order to analyze the possible role of the introduction in Italy of tenofovir (November 2002), Truvada ${ }^{\circledR}$ (September 2005), and Atripla ${ }^{\circledR}$ (October 2008), the calendar year was stratified into: 1988-1996, 1997-1998, 1999-2002, 2003-2005, 2006-2008, and 2009-2010. However, this did not lead to any appreciable difference across time periods.

Of note, a trend toward an increased risk of adverse events was observed for HIV genotype F1 (when 
Table 3 Characteristics of the study population $(n=1,096)$

\begin{tabular}{|c|c|c|c|c|}
\hline \multicolumn{3}{|l|}{ Factor/strata } & \multirow{2}{*}{$\begin{array}{l}\mathbf{n} \\
372\end{array}$} & \multirow{2}{*}{$\begin{array}{c}\% \\
33.9 \%\end{array}$} \\
\hline Female gender & & & & \\
\hline Non Italian nationality & & & 284 & $25.9 \%$ \\
\hline \multirow[t]{4}{*}{ Risk group } & \multicolumn{2}{|c|}{ Heterosexual } & 421 & $38.4 \%$ \\
\hline & \multicolumn{2}{|c|}{ Homo/bisexual } & 213 & $19.4 \%$ \\
\hline & \multicolumn{2}{|l|}{ IDU } & 199 & $18.2 \%$ \\
\hline & \multicolumn{2}{|c|}{ Other/unknown } & 263 & $24.0 \%$ \\
\hline \multirow[t]{3}{*}{ CDC stage } & \multicolumn{2}{|l|}{ A } & 495 & $45.2 \%$ \\
\hline & \multicolumn{2}{|l|}{ B } & 229 & $20.9 \%$ \\
\hline & \multicolumn{2}{|l|}{ C } & 372 & $33.9 \%$ \\
\hline \multirow[t]{6}{*}{ HIV subtype } & \multicolumn{2}{|l|}{ B } & 284 & $25.9 \%$ \\
\hline & \multicolumn{2}{|l|}{ 28_BF } & 84 & $7.7 \%$ \\
\hline & \multicolumn{2}{|l|}{ 17_BF } & 48 & $4.4 \%$ \\
\hline & \multicolumn{2}{|l|}{$\mathrm{F} 1$} & 27 & $2.5 \%$ \\
\hline & \multicolumn{2}{|l|}{ Other } & 48 & $4.4 \%$ \\
\hline & \multicolumn{2}{|l|}{ Unknown } & 557 & $50.8 \%$ \\
\hline \multirow[t]{4}{*}{ First-line anti-HIV therapy (encoding i) } & \multicolumn{2}{|c|}{ 2NRTI+1NNRTI } & 227 & $20.7 \%$ \\
\hline & \multicolumn{2}{|l|}{$2 \mathrm{NRTI}+1 \mathrm{PI}$} & 214 & $19.5 \%$ \\
\hline & \multicolumn{2}{|l|}{$2 \mathrm{NRTI}+1 \mathrm{Pl} / \mathrm{r}$} & 426 & $38.9 \%$ \\
\hline & \multicolumn{2}{|c|}{ Other combination } & 229 & $20.9 \%$ \\
\hline First-line anti-HIV therapy (encoding iv) & Truvada $^{(}+$ & & 47 & $4.3 \%$ \\
\hline & Atripla $^{\circledR}$ & & 14 & $1.2 \%$ \\
\hline & Reyataz $^{\circledR} \pm$ & bone & 22 & $2.0 \%$ \\
\hline & Kaletra $^{\circledR}+$ b & & 389 & $35.5 \%$ \\
\hline & Any other $N$ & & 165 & $15.0 \%$ \\
\hline & Any other $N$ & & 221 & $20.2 \%$ \\
\hline & Any other $N$ & & 18 & $1.6 \%$ \\
\hline & Other comb & & 220 & $20.1 \%$ \\
\hline Non-anti-HIV therapies (concomitant) & anti-TB & & 140 & $12.8 \%$ \\
\hline & anti-PCP & & 425 & $38.8 \%$ \\
\hline & anti-HCV & & 14 & $1.3 \%$ \\
\hline & other antibi & & 194 & $17.7 \%$ \\
\hline & other drugs & & 238 & $21.7 \%$ \\
\hline $\mathrm{HBsAg}$ & negative & & 978 & $89.2 \%$ \\
\hline & positive & & 56 & $5.1 \%$ \\
\hline & unknown & & 62 & $5.7 \%$ \\
\hline HCVAb & negative & & 771 & $70.3 \%$ \\
\hline & positive & & 247 & $22.5 \%$ \\
\hline & unknown & & 78 & $7.1 \%$ \\
\hline Discontinuation/switch for adverse events & & & 302 & $27.5 \%$ \\
\hline Discontinuation/switch for other causes & & & 618 & $56.4 \%$ \\
\hline Non-discontinued first-line anti-HIV therapies & & & 176 & $16.1 \%$ \\
\hline Years & 1988-1993 & 1994-1998 & 1999-2004 & $2005-2010$ \\
\hline Discontinuation/switch for adverse events & 17 & 92 & 108 & 85 \\
\hline Patients starting a first-line ART & 88 & 229 & 349 & 430 \\
\hline PYFU & 282.06 & 350.26 & 724.36 & 504.58 \\
\hline
\end{tabular}


Table 3 Characteristics of the study population $(n=1,096)$ (Continued)

\begin{tabular}{|c|c|c|}
\hline Numerical markers & Median & IQR \\
\hline Calendar year & 2003 & $1998-2006$ \\
\hline Days on first-line anti-HIV therapy & 379 & $131-855$ \\
\hline Age (years) & 36 & $31-43$ \\
\hline Years from the first HIV positive test & 0.5 & $0.1-3.4$ \\
\hline HIV-RNA $\log _{10}$ copies/mL & 4.8 & $4.7-5.2$ \\
\hline $\mathrm{CD}^{+} \mathrm{T}$ cells $/ \mathrm{mm}^{3}$ & 194 & $122-233$ \\
\hline
\end{tabular}

compared to genotype B). Moreover, unknown TGL showed a higher $\mathrm{RH}$ as compared to the corresponding "normal" (<150 mg/dL) category. We also formally tested for interactions between the calendar year and the efavirenz intake, using an ANOVA comparison on the nested models (i.e. with/without interaction), but the more complex model did not show a higher likelihood $(\mathrm{p}=0.5)$; the interaction term was not significant and the significant effect of efavirenz was canceled out.

In order to better assess the role of $\mathrm{CD}_{4}^{+} \mathrm{T}$ cell counts, different Cox regression models were fit with either the sole $\mathrm{CD}^{+}$or $\log \left(\mathrm{CD}^{+}\right)$cell $/ \mathrm{mm}^{3}$ count or including the full covariate set with the exception of the $\mathrm{CDC}$ stage. Only for the univariable $\log \left(\mathrm{CD} 4^{+}\right)$regression there was a significant $(\mathrm{p}<0.05)$ decreased hazard of an adverse event per $\log \left(\mathrm{CD}^{+}\right)$higher $(\mathrm{RH}=0.88,95 \%$ CI 0.79-0.99).

As a sensitivity analysis, we repeated the multivariable Cox regression using the subset of therapies posterior to 1998 ( $\mathrm{n}=779$, number of events $=193$, PYFU $=1228.948$, incidence of 0.16 with a $95 \%$ CI of 0.14-0.18), including only cART regimens (although $12 / 779$, i.e. $1.5 \%$, where not $2 \mathrm{NRTI}+1 \mathrm{NNRTI}$ or $2 \mathrm{NRTI}+1 \mathrm{PI} \pm \mathrm{r}$ regimens). The described relative hazards did not change, and in addition there was a significant reduced hazard of an adverse event for any other/unknown risk group as compared to the heterosexual category $(\mathrm{RH}=0.62,95 \% \mathrm{CI}$ 0.40-0.95, $\mathrm{p}=0.03)$, and a trend of increased hazard for nevirapine ( $\mathrm{RH}=4.42$, 95\% CI 0.92-21.12, $\mathrm{p}=0.06)$, fosamprenavir $(\mathrm{RH}=5.64,95 \% \mathrm{CI}$ 0.94-34.01, $\mathrm{p}=0.06)$, and nelfinavir $(\mathrm{RH}=4.42,95 \% \mathrm{CI} 0.97-20.22, \mathrm{p}=0.05)$. Moreover, in this model a significant higher risk of discontinuation for adverse events was demonstrated for HIV genotype F1 (RH 2.63, 95\% CI 1.22-5.67, p=0.013 when compared to genotype $\mathrm{B})$, while a trend was observed for genotype C (RH 2.24, 95\% CI 0.94-5.33, $\mathrm{p}=0.067$ ).

\section{Discussion and conclusion}

Since adverse events are the most frequent reason for first-line antiretroviral therapy discontinuation or switch, investigation of variables associated with their occurrence in a routine clinical practice setting is of increasing interest. Such an understanding is crucial to tailor antiretroviral regimens on patients' characteristics in order to increase the probability of cART tolerability.

In this study several demographic, clinical, laboratory and cART-related variables were investigated, providing useful information for the management of antiretroviral therapy. The prescribed antiretroviral drugs are main determinants of treatment discontinuation for toxicity. As expected, the use of older drugs such as zidovudine, stavudine, zalcitabine, didanosine and full-dose ritonavir was associated with increased risk of adverse events. However, these drugs are no longer recommended for first-line therapy because of their greater potential for toxicity [17]. When considering individual drugs currently recommended as preferred or alternative options in first-line regimens, an higher probability of treatment discontinuation for adverse events was observed for efavirenz (RH 2.4, 95\% CI 1.2-5.1, p=0.02). Despite efavirenz has demonstrated high virologic efficacy, both neuropsychiatric and neurocognitive toxicity associated with this drug are not negligible $[5,18]$. In a recent study, it was shown that nearly $20 \%$ of patients discontinue efavirenz due to central nervous system adverse events [19]. Since similar rates of virological response have been observed for other recommended regimens, this observation should be taken into account at the time of prescription of fist-line cART and close clinical monitoring should be warranted in efavirenz-treated patients. However, our analysis includes mainly patients treated with non-co-formulated efavirenz, since the single tablet regimen including efavirenz/tenofovir/emtricitabine is available in Italy from October 2008, and its availability seems to improve treatment convenience and related quality of life [20].

In this study, female patients showed a higher risk of treatment discontinuation for drug-related side effects, in accordance with previous results $[3,21]$. This might be due to peculiar gender-related pharmacokinetic characteristics which could influence drug exposure [21,22].

An interesting finding is the increased risk of discontinuation for adverse events observed in men who have sex with men. This could be ascribed to a different perception of side effects eventually related to sociocultural barriers, as described among vulnerable populations [23]. 

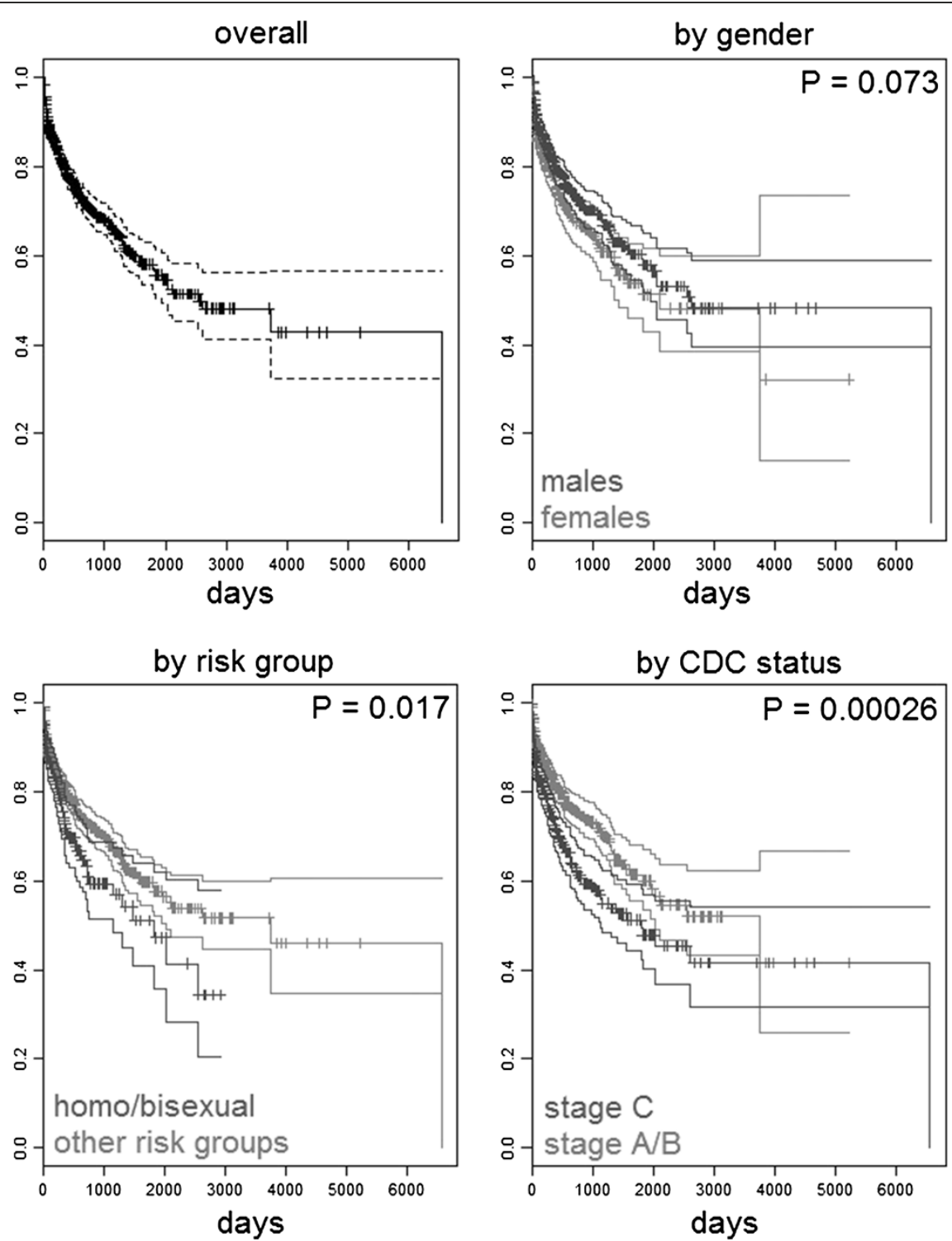

Figure 2 Kaplan-Meier estimations of the probability (with 95\% confidence intervals) to be free of adverse events after initiating a first-line antiretroviral therapy.

Unlike previous studies [2,3], in our population we did not observe a strong relation between discontinuation for toxicity and baseline $\mathrm{CD} 4^{+}$cells count or viral load.

Patients harboring HIV genotype F1 demonstrated an higher risk of treatment discontinuation for adverse events and a trend toward an association was observed for genotype C. F1 subtypes have been mostly detected in Latin America [24], where they were reported to be associated with faster HIV progression [25], and Central Africa [26]. F1-carrying patients in our sample were generally immigrants from poor resources countries often with non-steady residence in Italy. This may explain the higher, though non-significant, frequency of interruptions related to F1 subtypes (vs. B).
In agreement with previous studies [3], we confirmed the increased predisposition of older patients to discontinue antiretroviral therapy for side effects. This could be related to several factors, as an altered drug pharmacokinetic (e.g. modification of absorption, protein binding or distribution, impaired drug metabolism) and a potential for drug interactions with co-medications. Since our database does not include detailed data on co-medications other than drugs used for the treatment of opportunistic infections and co-infections, the potential role of drugdrug interactions as a major determinant of treatment discontinuation could not be assessed adequately.

Previous studies suggested that prescription of concomitant medications used for the treatment of opportunistic 
Table 4 Multivariable Cox model fit: relative hazards of adverse events, with two different antiretroviral therapy encodings $(n=1,096)$

\begin{tabular}{|c|c|c|c|c|}
\hline \multirow[t]{2}{*}{ Factor } & \multirow[t]{2}{*}{$\mathrm{RH}$} & \multicolumn{2}{|c|}{$95 \% \mathrm{Cl}$} & \multirow[t]{2}{*}{ p-value } \\
\hline & & Lower & Upper & \\
\hline calendar year (per more recent) & 1.01 & 0.96 & 1.07 & 0.6462 \\
\hline gender M vs. F & 0.52 & 0.38 & 0.71 & $<0.0001$ \\
\hline age per one year older & 1.04 & 1.02 & 1.05 & $<0.0001$ \\
\hline nationality non-Italian vs. Italian & 0.82 & 0.57 & 1.17 & 0.2724 \\
\hline nationality unknown vs. Italian & 1.08 & 0.62 & 1.87 & 0.7941 \\
\hline risk homo/bisexual vs. heterosexual & 2.03 & 1.40 & 2.94 & 0.0002 \\
\hline risk IDU vs heterosexual & 1.16 & 0.75 & 1.79 & 0.5153 \\
\hline risk other/unknown vs. heterosexual & 0.74 & 0.52 & 1.07 & 0.1090 \\
\hline years from first positive test & 0.99 & 0.96 & 1.02 & 0.3804 \\
\hline CDC stage $B$ vs. $A$ & 1.10 & 0.79 & 1.54 & 0.5716 \\
\hline CDC stage $C$ vs. A & 1.57 & 1.14 & 2.15 & 0.0051 \\
\hline HBsAg positive vs. negative & 1.67 & 1.04 & 2.69 & 0.0356 \\
\hline HBsAg unknown vs. negative & 1.11 & 0.54 & 2.28 & 0.7780 \\
\hline HCVAb positive vs. negative & 1.02 & 0.69 & 1.52 & 0.9109 \\
\hline HCVAb unknown vs. negative & 0.68 & 0.34 & 1.36 & 0.2766 \\
\hline CD4+ per cell $/ \mathrm{mm}^{3}$ higher & 1.00 & 1.00 & 1.00 & 0.8679 \\
\hline HIV-RNA per $\log _{10}$ higher & 0.85 & 0.68 & 1.07 & 0.1761 \\
\hline subtype 17 BF vs. B & 1.49 & 0.81 & 2.75 & 0.1973 \\
\hline subtype 28 BF vs. B & 0.96 & 0.56 & 1.65 & 0.8714 \\
\hline subtype 29 BF vs. B & 0.90 & 0.38 & 2.15 & 0.8113 \\
\hline subtype C vs. B & 1.87 & 0.83 & 4.18 & 0.1289 \\
\hline subtype F1 vs. B & 1.89 & 0.94 & 3.83 & 0.0747 \\
\hline subtype other vs. B & 1.46 & 0.75 & 2.86 & 0.2691 \\
\hline subtype unknown vs. B & 0.95 & 0.70 & 1.29 & 0.7441 \\
\hline bilirubin high vs. normal & 1.02 & 0.46 & 2.26 & 0.9576 \\
\hline bilirubin unknown vs. normal & 0.67 & 0.42 & 1.06 & 0.0845 \\
\hline hemoglobin normal vs. low & 0.97 & 0.66 & 1.40 & 0.8525 \\
\hline hemoglobin unknown vs. low & 0.91 & 0.47 & 1.78 & 0.7903 \\
\hline gammaGT high vs. normal & 0.93 & 0.62 & 1.39 & 0.7125 \\
\hline gammaGT unknown vs. normal & 1.12 & 0.77 & 1.64 & 0.5507 \\
\hline glucose diabetes vs. normal & 1.55 & 0.80 & 3.01 & 0.1959 \\
\hline glucose high vs. normal & 1.73 & 0.92 & 3.26 & 0.0888 \\
\hline glucose unknown vs. normal & 1.04 & 0.55 & 1.96 & 0.9142 \\
\hline GPT high vs. normal & 1.20 & 0.87 & 1.66 & 0.2757 \\
\hline GPT unknown vs. normal & 0.70 & 0.37 & 1.32 & 0.2691 \\
\hline HDL normal vs. low & 1.04 & 0.60 & 1.81 & 0.8911 \\
\hline HDL unknown vs. low & 0.97 & 0.35 & 2.67 & 0.9476 \\
\hline LDL high vs. normal & 1.51 & 0.56 & 4.03 & 0.4137 \\
\hline LDL unknown vs. normal & 1.62 & 0.58 & 4.51 & 0.3551 \\
\hline TGL high vs. normal & 0.95 & 0.63 & 1.42 & 0.8048 \\
\hline TGL unknown vs. normal & 1.65 & 1.11 & 2.44 & 0.0125 \\
\hline MDRD normal vs. low & 1.41 & 0.58 & 3.41 & 0.4430 \\
\hline MDRD unknown vs. low & 1.94 & 0.69 & 5.45 & 0.2098 \\
\hline
\end{tabular}

Table 4 Multivariable Cox model fit: relative hazards of adverse events, with two different antiretroviral therapy encodings $(n=1,096)$ (Continued)

anti-HCV therapy

$0.73 \quad 0.22$

2.41

0.6107

anti-TB therapy

$\begin{array}{lll}0.93 & 0.63 & 1.37\end{array}$

0.7013

anti-PCP therapy

other antibiotic therapy

$\begin{array}{lll}0.93 & 0.68 & 1.27\end{array}$

0.6533

other concomitant drugs

$\begin{array}{lll}0.99 & 0.71 \quad 1.37\end{array}$

0.9389

Atripla ${ }^{\circledR}$ vs. Truvada ${ }^{\circledR}+$ Sustiva ${ }^{\circledR}$

$\begin{array}{lll}0.76 & 0.56 & 1.03\end{array}$

0.0785

Reyataz ${ }^{\circledR}$ vs. Truvada $^{\circledR}+$ Sustiva $^{\circledR}$

$\begin{array}{lll}0.99 & 0.12 \quad 8.44\end{array}$

0.9901

Kaletra $^{\circledR}$ vs. Truvada ${ }^{\circledR}+$ Sustiva ${ }^{\circledR}$

$0.27 \quad 0.03$

2.27

0.2270

any other therapy vs.

$\begin{array}{lll}1.26 & 0.53 & 2.96\end{array}$

0.6025

Truvada ${ }^{\circledR}+$ Sustiva ${ }^{\circledR}$

$\begin{array}{lll}1.11 & 0.39 & 3.20\end{array}$

0.8408

any other NRTI+NNRTI vs.

$\begin{array}{lll}1.56 & 0.64 \quad 3.83\end{array}$

0.3267

Truvada ${ }^{\circledR}+$ Sustiva ${ }^{\circledR}$

any other NRTI+PI vs.

Truvada ${ }^{\circledR}+$ Sustiva ${ }^{\circledR}$

any other NRTI+PI/r vs.

Truvada ${ }^{\circledR}+$ Sustiva ${ }^{\circledR}$

Emtricitabine* (in the cART, yes vs. no)

$\begin{array}{lll}1.59 & 0.62 \quad 4.04\end{array}$

0.3339

Lamivudine* (in the CART, yes vs. no)

Abacavir* (in the cART, yes vs. no)

Zidovudine* (in the CART, yes vs. no)

Stavudine* (in the cART, yes vs. no)

Zalcitabine* (in the cART, yes vs. no)

Didanosine* (in the cART, yes vs. no)

Tenofovir* (in the CART, yes vs. no)

$3.89+1.38$

10.95

0.0101

$1.19+0.46=3.07$

0.7127

1.190 .46

2.09

0.5004

$1.21 \quad 0.70$

$\begin{array}{lll}2.33 & 0.93 \quad 5.87\end{array}$

0.0719

$3.51 \quad 1.34$

9.18

0.0107

$\begin{array}{lll}2.84 & 1.06 & 7.60\end{array}$

0.0375

$\begin{array}{lll}3.47 & 1.29 & 9.34\end{array}$

0.0136

$\begin{array}{lll}2.27 & 1.29 \quad 3.98\end{array}$

0.0042

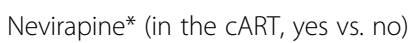

$2.00 \quad 0.65$

6.20

0.2282

Efavirenz (in the CART, yes vs. no)

$1.42 \quad 0.67$

2.98

0.3586

$\begin{array}{lll}2.40 & 1.14 & 5.03\end{array}$

0.0205

Atazanavir* (in the CART, yes vs. no)

$\begin{array}{ll}0.15 & 0.02\end{array}$

1.34

0.0898

Fosamprenavir* (in the CART, yes vs. no)

Indinavir* (in the CART, yes vs. no)

$2.77 \quad 0.76$

10.09

0.123

Lopinavir* (in the CART, yes vs. no)

$\begin{array}{ll}1.76 & 1.04\end{array}$

3.00

0.0357

Nelfinavir* (in the CART, yes vs. no)

$\begin{array}{lll}0.55 & 0.23 \quad 1.33\end{array}$

0.1843

Ritonavit full dose* (in the cART,

yes vs. no)

$\begin{array}{llll}1.37 & 0.66 & 2.86 & 0.396\end{array}$

$\begin{array}{lll}2.76 & 1.39 & 5.52\end{array}$

0.0039

$\begin{array}{lllll}\text { Saquinavir* (in the CART, yes vs. no) } & 1.75 & 0.91 & 3.36 & 0.0922\end{array}$

$\begin{array}{lllll}\text { Ritonavir boosting dose* (in the CART, } & 1.19 & 0.41 & 3.44 & 0.7527\end{array}$ yes vs. no)

*Substituting anti-HIV therapy encoding (iv) to (ii) and fitting with the other covariates (single drugs' RH are mutually adjusted). Note that both encoding (i) that compared $2 \mathrm{NRTI}+1 \mathrm{NNRTI}, 2 \mathrm{NRTI}+1 \mathrm{PI}, 2 \mathrm{NRTI}+1 \mathrm{PI} / \mathrm{r}$, others, and encoding (iii) that compared therapy combinations with a frequency of at least 10 , did not show significantly different hazards (at $\mathrm{p}=0.05$ level).

infections could increase the risk of discontinuation owing to cumulative toxicities or drug interactions [3]. In our population we did not observe an increased risk of discontinuation for adverse events in patients treated for PCP, TB or HCV co-infection. However, patients with 
AIDS-defining events were more likely to interrupt or switch cART for drug-related side effects.

Co-infection with HBV or HCV have been claimed as a predisposing factor for treatment discontinuation due to hepatic adverse events [9]; however, this association remain controversial $[2,3]$. In our population we did not observe a significant role of $\mathrm{HCV}$ co-infection, but HBsAg-positive patients showed an increased hazard of adverse events. The importance of co-infection with hepatitis viruses could be strictly related to the frequency of prescription of specific antiretroviral drugs, with older drugs bearing a higher risk of hepatotoxicity.

The calendar year was not showing an impact on the hazard of toxicity/allergy events. A similar observation has been previously described in other cohorts $[2,27]$. This could seem paradoxical since in recent years several drugs with better tolerability profile have been introduced in routine clinical practice. A possible explanation of this finding can rely on the increased number of alternative regimens that have become available in recent years; for this reason clinicians can be more prone to switch drugs also for less severe adverse events. Unfortunately, we could not verify this hypothesis since grading of clinical adverse events was not available in our database.

The potential association of treatment discontinuation for side effects and baseline chemical parameters has not been investigated in previous studies. Chemistry characteristic can represent important tools on the basis of which clinicians can choose the appropriate antiretroviral regimens in order to limit the occurrence of toxicities. In our population, we did not observe any association with the explored parameters; however, the relevant proportion of missing data could have influenced such finding masking the real effects in terms of increased/reduced hazard of adverse events occurrence. Moreover, only baseline markers were analyzed, while the effect of current markers may be crucial, for instance the raise levels of bilirubin during atazanavir-containing antiretroviral therapy [28]. We decided not to perform a time-dependent analysis given the high rate of missing information in the baseline variables. A few multi-centric HIV study cohorts in Italy, specifically the MASTER (www.mastercohort.it) and Icona (http:// www.fondazioneicona.org) foundations, and in Europe, including the Copenhagen HIV Programme and EuroSIDA (http://www.cphiv.dk) record such detailed information for all patients, besides the standard HIV serologic markers $[15,16]$.

Some limitations should be recognized when interpreting the results of our study. First, cART toxicity was analyzed considering only treatment modification, but clinical events or alterations in laboratory parameters not leading to treatment discontinuation were not investigated, thus leading to an underestimation of overall drug-related side effects. There might be a population bias, since the first-line anti-HIV therapies could have been tuned appositely on the patients' background, basing on the guidelines available at that time. This can be truer for drug combinations circulating for a longer time, whose adverse effect have been deeply disclosed. Since this study is retrospective, the bias cannot be ruled out even using strong selection criteria and a patient cohort with a high level of detail and follow up.

Another possible limitation of this study is that we conducted a cause-specific analysis, ignoring the potential effects of competing events in the survival analysis; such events may drive the happening of adverse effects, and surely a design of a competing-risk analysis after this study is warranted.

Given the current, fair, rate of virologic and immunologic successes of first-line anti-HIV antiretroviral therapies in the European Union and other developed countries [29-32], along with the decrease of drugresistance prevalence [33-39], the objective is now the prolongation of the therapy duration with the minimization of adverse events. Intolerance/toxicity still remains the major cause of drug discontinuation in Italy [40]. Therefore, an effort in gathering data from all available sources to assess more precisely prognostic factors and relative hazards of adverse events is warranted. Eventually, a personalized scoring system might be inferred, as it has been done with the prediction of virologic responses and time to virologic failure [41-44].

In conclusion, several predictors of treatment discontinuation for drug-related adverse events were investigated. These findings could help clinicians to identify individuals at higher risk of developing toxicity, thus allowing an improved prescription of antiretroviral regimens tailored on patients' characteristics. Moreover, these results suggest the importance of anticipating the probability of occurrence of adverse events in order to ensure close clinical and laboratory monitoring and adequate management of side effects which could improve the durability of cART.

\section{Additional file}

Additional file 1: Distribution of first-line anti-HIV therapies by calendar year.

\section{Abbreviations}

CART: Combination antiretroviral therapy; Cl: confidence intervals; CUSH: Catholic University of the Sacred Heart; gammaGT: gammaglutamyltransferase; GPT: Glutamate pyruvate transaminases; GFR: Glomerular filtration rate; HDL: High-density lipoprotein; LDL: Low-density lipoprotein; MDRD: Modification of diet in renal disease formula; NNRTI: Non-nucleoside reverse transcriptase inhibitor; NRTI: Nucleoside reverse transcriptase inhibitors; PCP: Pneumocystis jirovecii pneumonia; PI: Protease inhibitor; PI/r: PI 
boosted with ritonavir; PYFU: Person years of follow up; RH: Relative hazard; TB: Tuberculosis; TGL: Triglycerides; 95\% Cl: 95\% Confidence Interval.

\section{Competing interests}

MF received speakers' honoraria from Abbott Virology, Merck Sharp and Dohme and Janssen-Cilag. MZ received speakers' honoraria from Abbott Virology, Merck Sharp and Dohme, Janssen-Cilag, Bristol-Myers Squibb and Gilead Science. MC was an employee of Bristol-Myers Squibb from May 2010 to February 2011 and resigned before starting the present work. RC was advisor for Gilead and Janssen-Cilag, received speakers' honoraria from ViiV, Bristol-Myers Squibb, Merck Sharp and Dohme and Janssen-Cilag, and research support from "Fondazione Roma". SDG received speakers' honoraria from ViiV, Bristol-Myers Squibb, Merck Sharp and Dohme and Janssen-Cilag. All other authors: none to declare.

\section{Authors' contributions}

MCFP contributed to study design, data analysis and interpretation, and article writing; MF and MZ contributed to interpretation of data and article writing; IF, MC, AM, ADA, AB contributed to data collection; RC and SDG coordinated the project and contributed to interpretation of data. All authors reviewed the manuscript during preparation, provided critical feedback and approved the final manuscript.

\section{Acknowledgements}

No specific funding was received for this work.

\section{Author details}

${ }^{1}$ Clinical Infectious Diseases, Catholic University of Sacred Heart, Rome, Italy. ${ }^{2}$ Emerging Pathogens Institute \& Department of Pathology, Immunology and Laboratory Medicine, College of Medicine, University of Florida, Gainesville, Florida, USA. ${ }^{3}$ Viral Immunodeficiency Unit, National Institute for Infectious Diseases "Lazzaro Spallanzani", Rome, Italy. ${ }^{4}$ Clinical Department, National Institute for Infectious Diseases "Lazzaro Spallanzani", Via Portuense 292, 00149 Rome, Italy.

Received: 20 April 2012 Accepted: 1 November 2012

Published: 12 November 2012

\section{References}

1. Palella FJ Jr, Baker RK, Moorman AC, Chmiel JS, Wood KC, Brooks JT, Holmberg SD, HIV Outpatient Study Investigators: Mortality in the highly active antiretroviral therapy era: changing causes of death and disease in the HIV outpatient study. J Acquir Immune Defic Syndr 2006, 43:27-34.

2. Vo TT, Ledergerber B, Keiser O, Hirschel B, Furrer H, Battegay M, Cavassini M, Bernasconi E, Vernazza P, Weber R, Swiss HIV Cohort Study: Durability and outcome of initial antiretroviral treatments received during 2000-2005 by patients in the Swiss HIV Cohort Study. J Infect Dis 2008, 197:1685-1694.

3. Elzi L, Marzolini C, Furrer H, Ledergerber B, Cavassini M, Hirschel B, Vernazza P, Bernasconi E, Weber R, Battegay M, Swiss HIV Cohort Study: Treatment modification in human immunodeficiency virus-infected individuals starting combination antiretroviral therapy between 2005 and 2008. Arch Intern Med 2010, 170:57-65.

4. Strategies for Management of Anti-Retroviral Therapy/INSIGHT; DAD Study Groups: Use of nucleoside reverse transcriptase inhibitors and risk of myocardial infarction in HIV-infected patients. AIDS 2008, 22:F17-F24.

5. Ciccarelli N, Fabbiani M, Di Giambenedetto S, Fanti I, Baldonero E, Bracciale L, Tamburrini E, Cauda R, De Luca A, Silveri MC: Efavirenz associated with cognitive disorders in otherwise asymptomatic HIV-infected patients. Neurology 2011, 76:1403-1409.

6. Fabbiani M, Bracciale L, Doino M, D'Avino A, Marzocchetti A, Navarra P, Cauda R, De Luca A, Di Giambenedetto S: Tenofovir discontinuation could predispose to urolithiasis in atazanavir-treated patients. J Infect 2011, 62:319-321.

7. Islam F, Wu J, Jansson J, Wilson D: Relative risk of cardiovascular disease among people living with HIV: a systematic review and meta-analysis. HIV Med 2012. doi:10.1111/j.1468-1293.2012.00996.x. in press.

8. O'Brien ME, Clark RA, Besch CL, Myers L, Kissinger P: Patterns and correlates of discontinuation of the initial HAART regimen in an urban outpatient cohort. J Acquir Immune Defic Syndr 2003, 34:407-414.
9. Mocroft A, Phillips AN, Soriano V, Rockstroh J, Blaxhult A, Katlama C, Boron-Kaczmarska A, Viksna L, Kirk O, Lundgren JD, EuroSIDA Study Group: Reasons for stopping antiretrovirals used in an initial highly active antiretroviral regimen: increased incidence of stopping due to toxicity or patient/physician choice in patients with hepatitis C coinfection. AIDS Res Hum Retroviruses 2005, 21:743-752.

10. Yuan Y, L'italien G, Mukherjee J, lloeje UH: Determinants of discontinuation of initial highly active antiretroviral therapy regimens in a US HIVinfected patient cohort. HIV Med 2006, 7:156-162.

11. d'Arminio Monforte A, Lepri AC, Rezza G, Pezzotti P, Antinori A, Phillips AN, Angarano G, Colangeli V, De Luca A, Ippolito G, Caggese L, Soscia F, Filice G, Gritti F, Narciso P, Tirelli U, Moroni M: Insights into the reasons for discontinuation of the first highly active antiretroviral therapy (HAART) regimen in a cohort of antiretroviral naive patients. AIDS 2000, 14:499-507.

12. Lubomirov R, Colombo S, di lulio J, Ledergerber B, Martinez R, Cavassini M, Hirschel B, Bernasconi E, Elzi L, Vernazza P, Furrer H, Günthard HF, Telenti A, Swiss HIV Cohort Study: Association of pharmacogenetic markers with premature discontinuation of first-line anti-HIV therapy: an observational cohort study. J Infect Dis 2011, 203:246-257.

13. National Cholesterol Education Program (NCEP) Expert Panel on Detection, Evaluation, and Treatment of High Blood Cholesterol in Adults (Adult Treatment Panel III): Third Report of the National Cholesterol Education Program (NCEP) Expert Panel on Detection, Evaluation, and Treatment of High Blood Cholesterol in Adults (Adult Treatment Panel III) final report. Circulation 2002, 106:3143-3421.

14. Division of AIDS (DAIDS): Table for grading the severity of adult and pediatric adverse events. Publish date: December, 2004. Available at: http://www.niaid.nih.gov/LabsAndResources/resources/DAIDSClinRsrch/ Documents/daidsaegradingtable.pdf (13 March 2012, date last accessed).

15. Torti C, Lapadula G, Casari S, Puoti M, Nelson M, Quiros-Roldan E, Bella D, Pastore G, Ladisa N, Minoli L, Sotgiu G, Mazzotta F, Lo Caputo S, Di Perri G, Filice G, Tinelli C, Carosi G, EPOKA-MASTER Study Group: Incidence and risk factors for liver enzyme elevation during highly active antiretroviral therapy in HIV-HCV co-infected patients: results from the Italian EPOKAMASTER Cohort. BMC Infect Dis 2005, 5:58.

16. Reekie J, Reiss P, Ledergerber B, Sedlacek D, Parczewski M, Gatell J, Katlama C, Fätkenheuer $G$, Lundgren JD, Mocroft A, EuroSIDA study group: A comparison of the long-term durability of nevirapine, efavirenz and lopinavir in routine clinical practice in Europe: a EuroSIDA study. HIV Med 2011, 12(5):259-68.

17. Panel on Antiretroviral Guidelines for Adults and Adolescents: Guidelines for the use of antiretroviral agents in HIV-1-infected adults and adolescents: Department of Health and Human Services; 2011:1-167. Available at http:// www.aidsinfo.nih.gov/ContentFiles/AdultandAdolescentGL.pdf (13 March 2012, date last accessed).

18. Gazzard B, Balkin A, Hill A: Analysis of neuropsychiatric adverse events during clinical trials of efavirenz in antiretroviral-naive patients: a systematic review. AIDS Rev 2010, 12:67-75.

19. Scourfield A, Zheng J, Chinthapalli S, Waters L, Martin T, Mandalia S, Nelson M: Discontinuation of Atripla ${ }^{\circledR}$ as first-line therapy in HIV-1 infected individuals. AIDS 2012, in press.

20. Airoldi M, Zaccarelli M, Bisi L, Bini T, Antinori A, Mussini C, Bai F, Orofino G, Sighinolfi L, Gori A, Suter F, Maggiolo F: One-pill once-a-day HAART: a simplification strategy that improves adherence and quality of life of HIV-infected subjects. Patient Prefer Adherence 2010, 4:115-125.

21. Floridia M, Giuliano M, Palmisano L, Vella S: Gender differences in the treatment of HIV infection. Pharmacol Res 2008, 58:173-182.

22. Ofotokun I, Chuck SK, Hitti JE: Antiretroviral pharmacokinetic profile: a review of sex differences. Gend Med 2007, 4:106-119.

23. Robison LS, Westfall AO, Mugavero MJ, Kempf MC, Cole SR, Allison JJ, Willig JH, Raper UL, Wilcox CM, Saag MS: Short-term discontinuation of HAART regimens more common in vulnerable patient populations. AIDS Res Hum Retroviruses 2008, 24:1347-1355.

24. Aulicino PC, Bello G, Rocco C, Romero H, Mangano A, Morgado MG, Sen L: Description of the first full-length HIV type 1 subtype F1 strain in Argentina: implications for the origin and dispersion of this subtype in South America. AIDS Res Hum Retroviruses 2007, 23:1176-1182.

25. Teixeira SLM, Guimaraes ML, Leite T, Coelho A, Campos DP, Veloso V, Morgado MG: Disease progression in a cohort of HIV-1 positive patients from Rio de Janeiro, Brazil: potential role of HIV-1 subtypes and HLA-B alleles. Rome: 6th IAS Conference on HIV Pathogenesis, Treatment and Prevention; 2011. Abstract n CDA105. 
26. Taylor B, Sobieszczyk M, McCutchan F, Hammer S: The challenge of HIV-1 subtype diversity. N Engl J Med 2008, 358:1590-1602.

27. Braithwaite RS, Kozal MJ, Chang CC, Roberts MS, Fultz SL, Goetz MB, Gibert C, Rodriguez-Barradas M, Mole L, Justice AC: Adherence, virological and immunological outcomes for HIV-infected veterans starting combination antiretroviral therapies. AIDS 2007, 21:1579-1589.

28. Rekić D, Clewe O, Röshammar D, Flamholc L, Sönnerborg A, Ormaasen V, Gisslén M, Abelö A, Ashton M: Bilirubin-a potential marker of drug exposure in atazanavir-based antiretroviral therapy. AAPS J 2011, 13:598-605.

29. Lampe FC, Gatell JM, Staszewski S, Johnson MA, Pradier C, Gill MJ, de Lazzari E, Dauer B, Youle M, Fontas E, Krentz HB, Phillips AN: Changes over time in risk of initial virologic failure of combination antiretroviral therapy: a multicohort analysis, 1996 to 2002. Arch Intern Med 2006, 166:521-528,

30. Lampe FC, Smith CJ, Madge S, Kinloch-de Loes S, Tyrer M, Sabin CA Chaloner C, Youle M, Johnson MA, Phillips AN: Success of clinical care for human immunodeficiency virus infection according to demographic group among sexually infected patients in a routine clinic population, 1999 to 2004. Arch Intern Med 2007, 167:692-700.

31. Prosperi MC, Cozzi-Lepri A, Antinori A, Cassola G, Torti C, Ursitti MA, Pellizzer GP, Giacometti A, d'Arminio Monforte A, De Luca A, Icona Foundation Study Group: Favourable evolution of virologic and immunological profiles in treated and untreated patients in Italy in the period 1998-2008. HN Med 2011, 12:174-182.

32. Deeks SG, Gange SJ, Kitahata MM, Saag MS, Justice AC, Hogg RS, Eron J, Brooks JT, Rourke SB, Gill MJ, Bosch RJ, Benson CA, Collier AC, Martin JN, Klein MB, Jacobson LP, Rodriguez B, Sterling TR, Kirk GD, Napravnik S, Rachlis AR, Calzavara LM, Horberg MA, Silverberg MJ, Gebo KA, Kushel MB, Goedert JJ, McKaig RG, Moore RD: Trends in multidrug treatment failure and subsequent mortality among antiretroviral therapy-experienced patients with HIV infection in North America. Clin Infect Dis 2009, 49:1582-1590.

33. Di Giambenedetto S, Prosperi M, Fanti I, Bruzzone B, Paolucci S, Penco G, Meini G, Di Biagio A, Paolini E, Micheli V, Meraviglia P, Castelli P, Corsi P, Gonnelli A, Fabbiani M, Zazzi M, De Luca A, ARCA Collaborative Group: Update on emergence of HIV-1 resistance to antiretroviral drug classes in an Italian national database: 2007-2009. Clin Microbiol Infect 2011, 17:1352-1355.

34. Bannister WP, Cozzi-Lepri A, Kjær J, Clotet B, Lazzarin A, Viard JP, Kronborg G, Duiculescu D, Beniowski M, Machala L, Phillips A, EuroSIDA group: Estimating prevalence of accumulated HIV-1 drug resistance in a cohort of patients on antiretroviral therapy. J Antimicrob Chemother 2011, 66:901-911.

35. Prosperi MC, Mackie N, Di Giambenedetto S, Zazzi M, Camacho R, Fanti I, Torti C, Sönnerborg A, Kaiser R, Codoñer FM, Van Laethem K, Bansi L, van de Vijver DA, Geretti AM, De Luca A, SEHERE consortium: Detection of drug resistance mutations at low plasma HIV-1 RNA load in a European multicentre cohort study. J Antimicrob Chemother 2011, 66:1886-1896.

36. Bracciale L, Colafigli M, Zazzi M, Corsi P, Meraviglia P, Micheli V, Maserati R, Gianotti N, Penco G, Setti M, Di Giambenedetto S, Butini L, Vivarelli A, Trezzi M, De Luca A: Prevalence of transmitted HIV-1 drug resistance in HIV-1infected patients in Italy: evolution over 12 years and predictors. J Antimicrob Chemother 2009, 64:607-615.

37. Di Giambenedetto S, Bracciale L, Colafigli M, Cattani P, Pinnetti C, Bacarelli A, Prosperi M, Fadda G, Cauda R, De Luca A: Declining prevalence of HIV-1 drug resistance in treatment-failing patients: a clinical cohort study. Antivir Ther 2007, 12:835-839.

38. Di Giambenedetto S, Zazzi M, Corsi P, Gonnelli A, Di Pietro M, Giacometti A, Almi P, Trezzi M, Boeri E, Gianotti N, Menzo S, Del Gobbo R, Francisci D, Nerli A, Galli L, De Luca A, Antiretroviral Resistance Cohort Analysis Study Group: Evolution and predictors of HIV type- 1 drug resistance in patients failing combination antiretroviral therapy in Italy. Antivir Ther 2009, 14:359-369

39. May MT, Sterne JA, Costagliola D, Sabin CA, Phillips AN, Justice AC, Dabis F, Gill J, Lundgren J, Hogg RS, de Wolf F, Fätkenheuer G, Staszewski S, d'Arminio Monforte A, Egger M, Antiretroviral Therapy (ART) Cohort Collaboration: HIV treatment response and prognosis in Europe and North America in the first decade of highly active antiretroviral therapy: a collaborative analysis. Lancet 2006, 368:451-458.

40. Cicconi P, Cozzi-Lepri A, Castagna A, Trecarichi EM, Antinori A, Gatti F, Cassola G, Sighinolfi L, Castelli P, d'Arminio Monforte A, ICoNA Foundation Study Group: Insights into reasons for discontinuation according to year of starting first regimen of highly active antiretroviral therapy in a cohort of antiretroviral-naïve patients. HIV Med 2010, 11:104-113.

41. Prosperi MC, Altmann A, Rosen-Zvi M, Aharoni E, Borgulya G, Bazso F, Sönnerborg A, Schülter E, Struck D, Ulivi G, Vandamme AM, Vercauteren J, Zazzi M, EuResist and Virolab study groups: Investigation of expert rule bases, logistic regression, and non-linear machine learning techniques for predicting response to antiretroviral treatment. Antivir Ther 2009, 14:433-442.

42. Prosperi MC, Di Giambenedetto S, Fanti I, Meini G, Bruzzone B, Callegaro A, Penco G, Bagnarelli P, Micheli V, Paolini E, Di Biagio A, Ghisetti V, Di Pietro M, Zazzi M, De Luca A, ARCA cohort: A prognostic model for estimating the time to virologic failure in HIV-1 infected patients undergoing a new combination antiretroviral therapy regimen. BMC Med Inform Decis Mak 2011, 11:40

43. Larder BA, Revell A, Mican JM, Agan BK, Harris M, Torti C, Izzo I, Metcalf JA, Rivera-Goba M, Marconi VC, Wang D, Coe D, Gazzard B, Montaner J, Lane HC: Clinical evaluation of the potential utility of computational modeling as an HIV treatment selection tool by physicians with considerable HIV experience. AIDS Patient Care STDS 2011, 25:29-36.

44. Robbins GK, Johnson KL, Chang Y, Jackson KE, Sax PE, Meigs JB, Freedberg KA: Predicting virologic failure in an HIV clinic. Clin Infect Dis 2010, 50:779-786.

doi:10.1186/1471-2334-12-296

Cite this article as: Prosperi et al:: Predictors of first-line antiretroviral therapy discontinuation due to drug-related adverse events in HIV-infected patients: a retrospective cohort study. BMC Infectious Diseases 2012 12:296.

\section{Submit your next manuscript to BioMed Central and take full advantage of:}

- Convenient online submission

- Thorough peer review

- No space constraints or color figure charges

- Immediate publication on acceptance

- Inclusion in PubMed, CAS, Scopus and Google Scholar

- Research which is freely available for redistribution

Submit your manuscript at www.biomedcentral.com/submit
C) BioMed Central 